\title{
GCU
}

Glasgow Caledonian

University

University for the Common Good

\section{Factors influencing the prevalence of animal cruelty during adolescence}

Connor, M.; Currie, C.; Lawrence, A.

Published in:

Journal of Interpersonal Violence

DOI:

$10.1177 / 0886260518771684$

Publication date:

2021

Document Version

Author accepted manuscript

Link to publication in ResearchOnline

Citation for published version (Harvard):

Connor, M, Currie, C \& Lawrence, A 2021, 'Factors influencing the prevalence of animal cruelty during adolescence', Journal of Interpersonal Violence, vol. 36, no. 7-8, pp. 3017-3040.

https://doi.org/10.1177/0886260518771684

\section{General rights}

Copyright and moral rights for the publications made accessible in the public portal are retained by the authors and/or other copyright owners and it is a condition of accessing publications that users recognise and abide by the legal requirements associated with these rights.

Take down policy

If you believe that this document breaches copyright please view our takedown policy at https://edshare.gcu.ac.uk/id/eprint/5179 for details of how to contact us. 
1 Factors influencing the prevalence of animal cruelty during adolescence

2 Connor, M. ${ }^{1}$, Currie, ${ }^{2}{ }^{2}$, Lawrence, $A .{ }^{1}$

3 1. Animal Behaviour and Welfare, Scotland's Rural College (SRUC), W Mains Rd, Edinburgh, 4 Scotland, UK

5 2. Child and Adolescent Health Research Unit (CAHRU), School of Medicine, University of St

6 Andrews, St Andrews, Fife, Scotland, UK 


\section{Introduction}

Human maltreatment of non-human animals is a serious ethical and social problem. Maltreatment of animals is often complex and of varying degrees of severity. Various definitions of animal cruelty, maltreatment or abuse (hereafter referred to as animal cruelty) exist in the literature. Ascione (1993) defined animal cruelty as "socially unacceptable behavior that intentionally causes unnecessary pain, suffering, or distress to and/or death of an animal" (228). This definition provides an indication of the complexity that animal cruelty behaviour presents. Animal cruelty has been described to be a multidimensional construct including amongst other aspects severity, duration, frequency and empathy (Ascione, Thompson, \& Black, 1997; McPhedran, 2009b). Vermeulen distinguished between two dimensions; physical and mental animal cruelty. Physical animal cruelty and neglect can inflict pain, injuries and in very serious cases death of the animal whereas responses to mental cruelty might be less obvious but have the potential to cause negative emotional states (e.g. anxiety) and physiological stress resulting in overt behavioural expressions at a later date. Defining animal cruelty presents a difficulty for researchers due to varying perceptions for example age, gender, and culture of people e.g. participants' definitions of animal cruelty and researchers' definitions may be completely different and therefore validity of responses may be questionable (Pagani, Robustelli, \& Ascione, 2010). Furthermore, contrasting socially and culturally sanctioned (harmful) activities, resulting from differing attitudes towards different species are difficult to account for when defining animal cruelty (Becker, 2001). Consequently, creating a global definition of animal cruelty is challenging.

Cruelty towards animals has been suggested to be indicative of later interpersonal violence McPhedran (2009a) towards humans due to its deep historical and philosophical roots (Lea \& Stock)2007. Associations between childhood animal cruelty and interpersonal violence have been empirically investigated with criminal adults (Kellert \& Felthous, 1985) or described in case studies (see (Ascione, 1993) for review). Furthermore, a link between childhood animal cruelty and a spectrum of violent and anti-social behaviour has been described (McPhedran, 2009a). It has been argued that cruelty towards animals may be one of the first symptoms of conduct disorder appearing in children (Ascione \& Lockwood, 2001). Several family risk factors have been associated with childhood animal cruelty and adult violence. These risk factors include physical abuse within the family, sexual abuse, paternal 
alcoholism and absence, and general exposure to domestic violence (Duncan \& Miller, 2002). Not only experiencing family violence but also witnessing violence is considered to be a risk factor for disruptive children to be cruel to animals (Duncan, Thomas, \& Miller, 2005). Child and adolescents' animal cruelty incidences have been reported in different studies (Flynn, 1999a, 1999b, 2000; Miller \& Knutson, 1997). The reported proportion of participants engaging in animal cruelty acts varied a lot, however. Investigating a general adolescent sample resulted in between $12 \%$ to $50 \%$ of participants engaging in animal cruelty; $12 \%$ (Lucia \& Killias, 2011), 21 \% (Gullone \& Robertson, 2008), 50\% (Baldry, 2003). Investigated student samples ranged from $5 \%$ to $70 \%$ of participants engaging in animal cruelty; $4.3 \%$ (DeGue \& DiLillo, 2009)), 18\% (Flynn, 1999a), 73\% (Henry, 2004), 30\% (Henry \& Sanders, 2007). Half of the criminal participants engaged in animal cruelty acts during their childhood or adolescence (Hensley \& Tallichet, 2009). It has been reported that boys were more often engaged in cruelty acts than girls (Baldry, 2003, 2004; DeGue \& DiLillo, 2009; Flynn, 1999a, 1999b; Gullone \& Robertson, 2008; Henry, 2004; Lucia \& Killias, 2011) with older boys committing animal cruelty more often than younger boys (Baldry, 2003). No consensus could be reached on whether being cruel to animals is a group activity (Arluke, 2002) or whether adolescents act out alone (DeGue \& DiLillo, 2009; Lucia \& Killias, 2011).

Cruelty acts are often directed towards companion animals such as dogs and cats (DeGue \& DiLillo, 2009; Lucia \& Killias, 2011; Miller \& Knutson, 1997) but also towards small animals such as rodents, birds and reptiles (Flynn, 1999a, 1999b). Motivations for childhood animal abuse include peer pressure, sexual gratification, and post-traumatic play (Ascione et al., 1997). It can also be used as a vehicle for emotional abuse in the sense of hurting others by hurting animals (Ascione et al., 1997). Further motivations are to control an animal, to retaliate against an animal, to satisfy prejudice against a species or breed, to express aggression through an act of animal cruelty, to enhance one's own aggressiveness, to shock people for amusement, to retaliate against another person, to displace hostility from a person to an animal, and to act out non-specific sadism (Kellert \& Felthous, 1985).

The presented links need to be taken seriously on both human and animal welfare levels (Taylor \& Signal, 2005). Interest in preventing animal cruelty is now turning into an assessment of the feasibility of interagency cooperative models, whereby family and children's services and animal welfare organisations investigate both human and animal cruelty (Taylor \& Signal, 2005). 
Studies investigating animal cruelty employ a variety of different measures in different samples. Baldry (2004) for example measured animal cruelty using the P.E.T. - Physical and Emotional Tormenting Against Animals Scale (Baldry, 2004). This 9-item scale measures indirect or witnessed animal abuse as well as direct abuse by the respondent. It provides information about the prevalence and intensity of different types of violence against animals but no information about the animal involved (Baldry, 2004). The 'Boat inventory on Animal related Experiences' has been used in a number of studies (DeGue \& DiLillo, 2009; Flynn, 1999a; Henry \& Sanders, 2007; Miller \& Knutson, 1997). This measure assesses pet ownership and animal cruelty in a qualitative design where respondents have to describe their experiences with their pets or other animals. The 'Cruelty to Animals Inventory' developed by Daads and colleagues (2004) evaluates whether and how many times participants have hurt or have been cruel to an animal. It also includes the assessment of the type of animal involved. A study investigating college students provided their participants' with a predefined list of cruelty acts of which they could choose the acts they committed (Henry \& Sanders, 2007). This list included drowning, hitting or kicking, shooting, choking, burning or having had sex with an animal (Henry \& Sanders, 2007). Furthermore, single survey items such as asking people whether they have been cruel to animals were employed in a number of studies (Flynn, 1999a, 1999b; Hensley \& Tallichet, 2005a, 2005b, 2008, 2009; Hensley, Tallichet, \& Singer, 2006; Tallichet \& Hensley, 2004, 2005, 2009; Tallichet, Hensley, \& Singer, 2005). Measures used to date have collectively a number of potential short-comings that leave participants uncertain over questions such as: (a) The type of abuse should participants consider as constituting physical and mental abuse; (b) The degree of severity which is considered to be cruel; (c) The types of animals included in the researchers' cruelty definition and whether the term animals is restricted to vertebrates? The last question may play a central role as many invertebrate but also some vertebrate species are regarded as 'pests' posing a perceived danger or nuisance to humans.

\section{Rationale of the present study}

The combined information of existing research reveals that animal cruelty is prevalent in society with an onset during childhood, that there are links between animal cruelty and other forms of interpersonal violence and that both animal and human welfare are compromised. However, the majority of studies have used a retrospective approach to assess 
animal cruelty with either students (Flynn, 1999a, 1999b; Henry, 2004), or criminals (Miller \& Knutson, 1997; Simons, Wurtele, \& Durham, 2008; Tallichet \& Hensley, 2004). Only a few studies have used non-clinical populations to investigate animal cruelty in adolescents and these studies have applied different measures with varying cruelty definitions (Baldry, 2003, 2004; Gullone \& Robertson, 2008; Lucia \& Killias, 2011). Furthermore, the applied cruelty measures do not define the target animals to be considered and do not distinguish between physical and mental cruelty. Therefore, the information available cannot be generalised and may not be transferable to non-clinical populations. The present study addresses these gaps in the existing literature by: (1) investigating the prevalence of animal cruelty in a nonclinical population of adolescents providing a detailed definition of animal cruelty and a detailed description of the animals to be considered. Furthermore, different types of animal cruelty were assessed over a pre-defined time frame (only comprising adolescent years) including accidental cruelty, deliberate cruelty and neglect. (2) The present study also investigates potential predictors of animal cruelty in a non-clinical sample including sociodemographic variables such as pet-ownership, gender and family affluence, and the prevalence of anti-social behaviour in combination with the perceived acceptability of animal cruelty in society.

\section{Methods}

\section{Questionnaire}

In order to account for schools varying opportunities to access online surveys a paper pencil and an identical online questionnaire were created. For a paper-pencil version Snap Surveys software was used and Bristol Online Surveys (BOS) software was used to create an identical online version of the survey questionnaire. The questionnaire was designed to be completed during one teaching unit (maximum $45 \mathrm{mins}$ ). The questionnaire was administered during class time and teachers were free to choose during which class the questionnaire was administered. However, teachers choose classes where all students participated in the study. Ethical consent for the questionnaire was gained from the University of St. Andrews Medical School. Prior to sampling schools, local authority consent was gained. The online questionnaire was sent out to schools. 
Recruitment

In order to access Scottish schools all 32 local authorities ${ }^{i}$ were approached and further ethical approval was sought. As a result 11 (34\%) local authorities granted their approval; some of them provided the schools to approach whereas others did not. Therefore, head teachers of schools provided were approached and for the other local authorities we approached the last alphabetical secondary school. Head teachers received an invitation email and if no reply was received within 4 weeks an additional invitation letter was sent to the respective schools. Furthermore, schools were also contacted via phone to arrange the research. Schools were offered both the online version providing a link to the questionnaire and the paper pencil version. Furthermore, 75 private schools in Scotland were approached of which 21 read the invitation and one school agreed to participate in the study. Since the response rate was very low we additionally recruited via snowball sampling and a Biology teachers' network. Recruitment of schools in England and Wales did not require approval from local authorities and schools were therefore contacted directly. Similarly we approached the last alphabetical secondary school of each county. The response rate was also very low, the online questionnaire was completed by all English $(n=143)$ and Welsh $(n=7)$ participants completed the survey. All schools were offered free animal welfare education material and/or a visit by an animal welfare scientist to give a talk. Due to the variety of sampling approaches it is not possible to calculate a response rate. There were no gender or age differences between the two questionnaire dissemination strategies and consequently all participants were analysed as a single sample. The questionnaire was completed during school hours independently of which version adolescents received.

\section{Measures}

The questionnaire explored several constructs related to perceptions of animals but only measures relevant to animal cruelty will be presented here. At the beginning of the questionnaire adolescents were asked socio-demographic questions such as age, gender, pet ownership and self-reported living area (town, village or farm were coded as rural and city and sub-burb were coded as urban). Pet ownership was assessed using an adapted version of the Boat Inventory (Boat, 1999)

Adolescent's social economic status was assessed using the Family Affluence Scale (FAS), which was developed for an international study on school-aged children's health 
(Batista-Foguet, Fortiana, Currie, \& Villalbii, 2004). This scale assessed adolescents' socialeconomic status utilising material markers such as number of computers, cars and holidays.

In order to investigate self-reported animal cruelty behaviour, items concerning deliberate cruelty but also accidental cruelty and neglect were created (based on Daad, 2004). In total 11 items (Table 1) were used to assess animal cruelty in terms of accidental cruelty (e.g. frightening an animal accidentally), deliberate cruelty (e.g. hurting an animal on purpose) and neglect (e.g. forgetting to feed an animal). Cruelty acts were assessed over the last twelve months offering the answer categories never, 1-2 times, 2-5 times and more than 5 times. The question clearly stated that only cruelty acts against mammals (e.g. pets, farm and wild animals), birds, reptiles (e.g. lizards, snakes), amphibians (e.g. frogs) and fish should be taken into account. It further stated that acts towards insects (e.g. flies, bees, mosquitos) or molluscs (e.g. slugs and snails) should not be recorded when answering the question. These items were then used to create another set of items to investigate adolescents' perceptions of the acceptability of animal cruelty (Table 2). In total 12 items were used to evaluate acceptability of animal cruelty. Participants were asked to rate the acceptability of animal cruelty on a 6 point likert scale ranging from $1=$ not at all acceptable to $6=$ very acceptable.

Problem (anti-social) behaviour was assessed using adapted items from (Loeber, Farrington, Stouthamer-Loeber, \& Van Kammen, 1998). Items were rephrased to make them applicable to a British context after pre-testing the questionnaire (for example movie was replaced with film. Furthermore, dichotomous answering categories (yes/no) were changed into how many times in the past 12 months problem behaviours have occurred offering the options never, 1-2 times, 3-4 times, 5-6 times and more often. In total 9 items were used to form the problem behaviour measure: In the last 12 months how often have you done the following things? (a) cut classes or stayed away from school without permission (b) taken a car or other vehicle without owner's permission, just to drive around (c) been drunk in a public place (d) broke in or tried to break into a building just for fun or to look around (e) thrown objects such as rocks or bottles at people to hurt or scare them (f) sneaked into a movie, ballgame or something like that without paying (g) steal money or take something that did not belong to you (h) beat up someone or fought someone physically because they made you angry (i) purposely damaged or destroyed property that did not belong to you.

Development of the questionnaire was assisted by DEFRA (Department for Environment, Food and Rural Affairs in the UK), animal welfare charities and organisations 
and secondary school children and teachers who helped evaluate applicability and content validity. The questionnaire was approved by the ethics committee of the University of St. Andrews and was pre-tested with 87 secondary school children.

At any point during the development and also during the data collection phase, children were free to decide whether they wanted to take part or not. Children could exit the questionnaire at any time or leave questions blank in the paper pencil version without consequences. Missing values in the data set were not replaced and therefore the number of respondents varies in the analysis.

\section{Data analysis}

Paper pencil questionnaires were scanned using the SnapSurvey Software, data obtained online were extracted from BOS and merged with the paper pencil data in SPSS 22 . Data were analysed using the statistical package SPSS 22. Descriptive statistics were used to provide sample descriptions. Differences in count data were analysed using $\chi^{2}$ statistics. Reliability of the measures applied was analysed using Cronbach's alpha. Exploratory factor analysis with principle components as extraction method was used to investigate the underlying structure of adolescents' animal cruelty behaviour. Mean differences were analysed using t-test statistics or Analysis of Variance (ANOVA), effect sizes were calculated using means and standard deviations and are presented as Cohen's $\mathrm{d}$. A general linear model with repeated measures was used to evaluate differences between the cruelty components. A multiple regression analysis using the enter method was applied to investigate predictors of deliberate animal cruelty.

\section{Results}

\section{Participants}

A total of 979 adolescents participated in the survey questionnaire of which $83.6 \%$ (N $=764)$ lived in Scotland, $15.6 \%(n=143)$ lived in England and $0.8 \%(n=7)$ lived in Wales. Due to the unequal group sizes no country comparisons were conducted and the whole sample was analysed together. Forty-three per cent $(n=419)$ of the participants were male, $51 \%(n$ $=497)$ of the participants were female and six per cent $(N=63)$ did not report their gender. The mean age for all participants was 15.1 years $(S D=1.57)$. Boys were on average 15 years old $\left(\mathrm{SD}_{\text {boys }}=1.51\right)$ and girls were on average 15.2 years $\left(\mathrm{SD}_{\text {girls }}=1.61\right)$ old. Fifty five per cent 
( $n=539)$ of adolescents stated they lived in urban areas and 32\% $(N=306)$ indicated they live in rural areas; $14 \%(n=134)$ of adolescents didn't report where they lived. When comparing valid answers with the census data of Scotland the rural urban distribution of 12 to 17 year olds only slightly varies from the Scottish average (urban sample $=63.6 \%$, urban census $=$ 66.75 , rural sample $=36.6 \%$, rural census $=33.3 \%$ ).

Most adolescents $(n=832,91.6 \%)$ reported that they had lived with a pet in the past, and $73.9 \%(n=666)$ of the adolescents said they currently live with a pet which is comparable with other data published on pet ownership in the UK (Marsa-Sambola et al., 2016; Murray, Browne, Roberts, Whitmarsh, \& Gruffydd-Jones, 2010). Seventy-four percent of boys $(n=303)$ and girls $(n=359)$ reported having a pet. Similarly, $71 \%(n=372)$ of urban adolescents reported having a pet whilst $80 \%(n=245)$ of rural adolescents reported having a pet $\left(\chi^{2}=\right.$ $15.2, p=.001)$.

The most common pets were fish $(n=405)$, followed by dogs $(n=368)$, hamsters and guinea pigs $(n=341)$, and cats $(n=240)$. Girls had significantly more hamsters and guinea pigs $\left(\chi^{2}=12.72, p<.001\right)$ and rabbits $\left(\chi^{2}=4.74, p=.030\right)$ than boys. There were no gender differences regarding the other animals (dogs, cats, birds, fish, horse, mice, wild animals and reptiles) that adolescents reported living with.

There were differences between rural and urban adolescents regarding pets living in the house and the type of pet they would have in their family. Rural adolescents had significantly more cats than urban adolescents $\left(\chi^{2}=8.48, p=.014\right)$. Furthermore, rural adolescents reported living less with birds $\left(\chi^{2}=8.46, p=.015\right)$, fish $\left(\chi^{2}=26.36, p<.001\right)$, and mice $\left(\chi^{2}=14.39, p<.001\right)$. However, rural adolescent families reported living significantly more with horses $\left(\chi^{2}=24.08, p<.001\right)$, wild animals $\left(\chi^{2}=13.26, p<.001\right)$, and other animals $\left(\chi^{2}=32.4, p<.001\right)$ such as sheep and cows.

A composite score was calculated for family affluence, which divides adolescents into three groups; low, medium and high affluence. There was almost an equal distribution with $29.2 \%(N=286)$ of the adolescents reporting low family affluence, $36.3 \%(N=355)$ reporting medium family affluence and $34.5 \%$ (338) of adolescents reporting high family affluence.

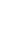
9 
Animal cruelty

In total 11 items were used to measure self-reported animal cruelty. Analysis shows a good reliability Cronbach's $\alpha=.793$. Adolescents in this sample generally report low levels of animal cruelty $(M=1.32, S D=0.35, n=837)$. The underlying structure of adolescents' animal cruelty behaviour was investigated using exploratory factor analysis (Table 2), and results reveal that adolescents show different types of cruelty towards animals. An item content analysis indicates that items containing words such as 'on purpose' load together; these components were subsequently labelled as deliberate cruelty (Cronbach's $\alpha=.682, N=5$ ). Items containing 'accidental' loaded on a second factor and were labelled accidental cruelty (Cronbach's $\alpha=.698, N=3$ ). The third component comprised items relating to forgetting to feed or water a pet and were labelled neglect (Cronbach's $\alpha=.639, N=3$ ). These three components account for $56.7 \%$ of the variance. Adolescents reported that they had been engaged in accidental animal cruelty more often $(M=1.58, S D=0.57, n=837)$ than in deliberate cruelty $(M=1.24, S D=0.41, n=837, t=18.506, \mathrm{df}=836, p<.001)$ and neglect $(M$ $=1.18, S D=0.37, n=833, t=-20.423, \mathrm{df}=832, p<.001)$. In order to test that these differences are independent from the large sample size Cohen's d was calculated as a measure of effect size. Cohen's $d$ for the accidental vs. deliberate cruelty was 0.674 and for the accidental cruelty vs. neglect was 0.818 . Both effect sizes suggest strong effects. $54.4 \%(n=455)$ of adolescents reported to have never been engaged in deliberate cruelty acts (this analysis only takes adolescents into account who answered all cruelty questions).

A small but significant difference resulted comparing reported neglect between boys and girls; boys reported higher levels of neglect than girls $p=.024$ (a detailed analysis of all comparisons can be found in Table 3). Effect size for this difference is small $d=.154$. Differences in reported neglect were also present between pet owners and non-pet owners $p<.000$, with the effect size of $d=.436$ suggesting a medium strong effect. Those differences remain when analysing pet ownership in dependence of gender, living area and age group (Table 3). Furthermore, a small difference $(p=.033, d=.197)$ in reported neglect was found analysing for family affluence with adolescents reporting medium family affluence stating higher levels of neglect than adolescent's reporting high family affluence (Table 3). No differences were observed comparing different age groups or urban and rural adolescents. 

13 year olds and $>16$ year olds $p=.017$, rural and urban adolescents $p=.014$, and between pet owners and non-pet owners $p=.000$. Effect sizes range from small to medium strong effects (Table 3). Girls, older adolescents, urban and non-pet owning adolescents reported lower levels of accidental cruelty than boys, younger adolescents, rural and pet-owning adolescents. Small gender differences are shown between urban boys and girls $(t(420.4)=$ 2.49, $p=.013, d=.219$ ) but not between rural boys and girls. Differences between pet and non-pet owners are constant and can also be shown when analysing the age groups separately $(12-13$ year olds: $t(294)=2.38, p=.018, d=.336,14-15$ year olds: $t(349)=2.22, p$ $=.027, d=.258,>16$ year olds: $t(105.8)=4.02, p=.000, d=.652)$. Furthermore, similar differences were found when analysing rural and urban adolescents separately (urban: $t$ (485) $=3.33, p=.001, d=.339$, rural: $: t(273)=2.14, p=.034, d=.347)$.

Self-reported deliberate cruelty differs between boys and girls $(p<.000)$ with boys reporting higher levels than girls and between rural an urban adolescents $(p=.012)$ with rural adolescents reporting higher levels than urban adolescents (Table 3). Gender differences are also prominent when investigating rural and urban adolescents separately for both living areas (urban: $t(316.3)=4.79, p=.000, d=.448$, rural: : $t(199.7)=3.07, p=.002, d=.364)$. Furthermore, gender differences were also observed in 12-13 year olds and 14-15 year olds (12-13 year olds: $t(243.7)=2.42, p=.016, d=.280,14-15$ year olds: $t(261)=4.53, p=.000, d$ $=.487)$ but not in adolescents older than 16 years. Small differences were observed comparing adolescents of varying family affluence (Table 3). Adolescents of medium family affluence reported higher levels of deliberate cruelty than adolescents of low family affluence $(p=.005)$.

\section{Acceptability of animal cruelty}

The 12 items assessing acceptability of animal cruelty showed a good overall reliability (Cronbach's $\alpha=.849, N=12$ ). Results show that four components can be extracted accounting for $73.1 \%$ of the variance (Table 2 ). Similarly to cruelty behaviour an item content analysis was used to label the factors. Component 1 represents items concerning neglect (Cronbach's $\alpha=.727, N=2, M=1.88, S D=.90)$, component 2 comprises items about deliberate mental cruelty (Cronbach's $\alpha=.768, N=3, M=1.49, S D=.75$ ), component 3 items about accidental 
cruelty (Cronbach's $\alpha=.936, N=3, M=2.26, S D=1.21$ ), and component 4 includes items about deliberate physical cruelty (Cronbach's $\alpha=.736, N=2, M=1.15, S D=.53$ ). PCA loadings suggest that the item 'kill an animal' loads on the factor labelled deliberate physical cruelty (Table 2), however reliability analysis suggest removing the item to increase reliability from Cronbach's $\alpha=.549$ to Cronbach's $\alpha=.736$. Consequently the item was removed for further analysis. A general linear model with repeated measures was used to evaluate differences between the cruelty components. Results show that the acceptability of different types of animal cruelty is different $(F(1.93 / 1589.94)=368.18, p=.000)$. Pairwise comparisons reveal differences between all pairs were $p<.000$. Deliberate physical animal cruelty $(M=$ $1.15, S E=0.02)$ is the least accepted type of cruelty, followed by deliberate psychological cruelty $(M=1.49, S E=0.03)$, neglect $(M=1.79, S E=0.03)$ and accidental cruelty respectively $(M=2.16, S E=0.04)$. Gender differences were found for the acceptability of neglect $(t(737.4)$ $=2.04, p=.042, d=.143)$, deliberate physical cruelty $(t(261)=4.53, p=.000, d=.487)$ and accidental cruelty $(t(503.9)=3.76, p=.000, d=.296)$ with boys finding all three types of cruelty more acceptable than girls (Table 5). However, effect sizes indicate small differences. Differences in acceptability of deliberate physical $(F(2)=4.86, p=.008)$ and psychological animal cruelty $(F(2)=7.63, p=.000)$ could also be observed comparing the different age groups (Table 5). Post-hoc tests reveal differences between $14-15$ year olds and $>16$ year olds with the younger ages showing greater acceptability than the older adolescents. Effect sizes indicate medium strong to strong effects. Differences in socio-economic status were only present for the acceptability of psychological cruelty. However, the effect size $d=.232$ is small.

Furthermore, anti-social behaviour was evaluated; reliability of the scale used to measure anti-social behaviour was high Cronbach's $\alpha=.903, \mathrm{~N}=9$ and a mean score was created the lower the score the less adolescents reported anti-social behaviour. In general boys $(M=1.33, S D=.70, n=312)$ show higher levels of anti-social behaviour $(t(420.8)=4.87$, $p<.001, d=.363)$ than girls $(M=1.13, S D=.34, n=414)$. A medium strong correlation exists between antisocial behaviour and deliberate animal cruelty $r=.334, p<.001$. There was no significant correlation between antisocial behaviour and neglect. 
A multiple regression analysis (Table 6) was used to investigate predictors of deliberate animal cruelty. Predictor variables were acceptability of different types of animal cruelty, anti-social behaviour and demographic variables including, gender, pet ownership and family affluence. All predictor variables explain a significant amount of the variance in deliberate animal cruelty $\left(F(10,648)=45.4, p<.001, R^{2}=.41 R^{2}\right.$ adjusted $\left.=.40\right)$. Inspection of tolerance levels show low levels of multicollinearity (observed levels of tolerance are between .370 and .958). The analysis shows that the acceptability of both physical and psychological deliberate cruelty are strong predictors for deliberate animal cruelty (Table 6). Furthermore, anti-social behaviour and adolescent's living place are also part of the model and explain a small but significant amount of the variance.

\section{Discussion}

The present study explored the prevalence of animal cruelty in a non-clinical sample of adolescents. It used a new approach to assessing animal cruelty that distinguished between deliberate and non-deliberate animal cruelty, and where adolescents received information about what type of animals to include when reporting cruelty acts. Furthermore, the study included a timeframe of the last 12 months to assess cruelty acts enabling adolescence to provide more accurate assessments of their behaviours. Assessing animal cruelty retrospectively without providing a time frame may bias the accuracy of the recall especially when experiences rely on judgement and interpretation (Hardt \& Rutter, 2004). Providing a specific time frame, which does not reach too far into the past, takes account of recall bias and provides a more accurate evaluation of the behaviour.

For this study only vertebrate animals were included since the UK Animal Welfare Act from 2006 only protects vertebrate species due to a lack of evidence on sentience in invertebrates (see http://www.legislation.gov.uk/ukpga/2006/45/notes/contents; although note that UK animal experimentation legislation does provide protection for cephalopods; see https://www.gov.uk/government/publications/consolidated-version-of-aspa-1986). This may differ between countries and needs to be taken into account when evaluating animal cruelty. When analysing all cruelty acts together, results show low levels of reported animal cruelty in general $(M=1.32, S D=0.35)$. However, exploratory factor analysis revealed three 
types of animal cruelty: accidental animal cruelty, neglect and deliberate animal cruelty confirming our initial distinction between deliberate and non-deliberate cruelty acts. Examples of deliberate animal cruelty include 'hurting an animal on purpose' and for deliberate mental animal cruelty 'annoying or frightening an animal on purpose'. Half of the adolescents $(n=300)$ reported to have been engaged in deliberate animal cruelty within the last twelve months on at least one or two occasions. These numbers seem to be consistent with previous findings (Flynn, 2001; Gullone \& Robertson, 2008). Nonetheless, it has to be noted that currently no existing measure of animal cruelty includes a timeframe for cruelty acts unlike the present study which used a time frame of 12 months. Since it is not specified in the literature as to when these animal cruelty acts were conducted and how often animals have been perpetrated during participants' childhood it is difficult to compare the findings of the present study with previous work. Furthermore, adolescents also reported to have been involved in accidental animal cruelty more often than in deliberate cruelty or neglect. This result shows the necessity to differentiate between cruelty acts, as accidental animal cruelty may bias prevalence of animal cruelty acts especially in samples with a high number of pet-owners. Pet-owners show significantly higher accidental animal cruelty and neglect than non-pet-owners. A simple explanation for this is that the chances of accidentally harming an animal are higher when owning a pet compared to not owning a pet. It has to be noted that both pet owners and no-pet-owners answered the questions regarding neglect. Participants had the option to choose never (which is coded as 1). The mean for non-pet owners shows that non-pet owners most often chose never $(1)(M=1.07$, $S D=0.29$ ). We don't specify as to whether participants should think of their own pet (which they don't have in this case). We only analysed current pet-ownership so it could well be that current non-pet owners have had a pet in the last 12 months but not at the time when the questionnaire was conducted or they were looking after someone else's pet, so they could potentially have been involved in neglect. Since rural adolescents reported to own pets more often than urban adolescents, rural adolescents also reported higher accidental cruelty acts. It has to be noted that younger adolescents show higher levels of accidental cruelty than older ones despite not differing in pet ownership. This indicates that adolescents may learn to be more careful with pets due to gaining more responsibility and knowledge which has been shown to occur in other studies (Covert, Whiren, Keith, \& Nelson, 1985). The present study reveals gender differences with medium strong effect 
sizes, with boys reporting higher levels of deliberate animal cruelty than girls. Studies investigating non-clinical samples retrospectively also found boys admitting more cruelty acts than girls (Becker, Stuewig, Herrera, \& McCloskey, 2004; Flynn, 1999a).

To evaluate the acceptability of animal cruelty, items were created on the basis of items used to measure the prevalence of animal cruelty. Therefore, items didn't describe specific cruelty acts nor include different levels of severity. Exploratory factor analysis suggests a four factor solution; acceptability of neglect, acceptability of accidental cruelty, acceptability of deliberate physical and acceptability of deliberate mental animal cruelty. Results show that deliberate physical cruelty is the least accepted form of animal cruelty followed by deliberate mental animal cruelty, neglect and accidental cruelty respectively. It has to be noted that neglect was assessed using items such as 'forgetting to feed an animal' or 'leaving an animal alone with enough food and water for a few days'. These are rather mild forms of neglect and may bias the acceptability of neglect, which can potentially have severe negative outcomes for the animals involved. When evaluating the acceptance of animal cruelty adolescents clearly distinguish between deliberate physical and mental cruelty, with physical cruelty evaluated as the least acceptable form of animal cruelty. Whilst factor scores indicated the inclusion of the item 'kill an animal' into deliberate physical cruelty, reliability analysis suggested removing that item. As the purpose of killing was not stated within the item it may have been difficult for the participants to judge the acceptability of killing an animal. Some participants could evaluate killing an animal for food in general or more specifically in a humane way as being acceptable. Other participants may have considered killing an animal for fun or out of curiosity and regard such actions as unacceptable. If an item on killing animals is to be included in future research the purpose of killing should be clearly stated.

The present study found weak but significant gender differences for the acceptability of deliberate physical cruelty, acceptability of neglect and acceptability of accidental cruelty but not for the acceptance of deliberate mental cruelty. Male adolescents in general had higher levels of acceptability for all types of cruelty acts than females. Studies have shown that attitudes towards the treatment of animals differ between males and females (Herzog, 2007). However, the studies reviewed by Herzog (2007) mostly concern attitudes towards animal experimentation and not the acceptability of animal cruelty. Nonetheless, the authors 
conclude that women generally show more concern for the welfare of animals than men and that women are more sympathetic to the treatment of animals than men (Herzog, 2007). It has also been shown that girls show higher levels of attachment to their pets than boys (Marsa-Sambola et al., 2016) and women are more empathetic towards animals (Paul, 2000).

Predictors of deliberate animal cruelty were evaluated and results show that participants' acceptability of deliberate cruelty, both physical and mental, are highly predictive for committing deliberate cruelty. Furthermore, whether participants live in rural or urban areas and their reported anti-social behaviour are small but significant contributors to committing deliberate cruelty. Measured predictor variables account for about $41 \%$ of the explained variance in a non-clinical sample. It has been empirically shown that childhood animal cruelty has an association with interpersonal violence (Kellert \& Felthous, 1985). A medium strong correlation was found between deliberate cruelty and anti-social behaviour supporting the hypothesis that animal cruelty is more common in children with anti-social personality traits (Gleyzer, Felthous, \& Holzer, 2002). The measure used to assess anti-social behaviour comprises different aspects but only includes one item, which measures violence. A measure specifically addressing interpersonal violence may have resulted in stronger correlations. In order to explain the remaining amount of variance family risk factors and witnessing violence can be taken into account (Duncan et al., 2005). However, it is difficult to include those family risk factors when investigating a non-clinical sample of adolescence recruited through schools since this could cause distress in affected adolescents. Therefore, the present study did not employ a measure of family risk factors.

In conclusion the present study shows for the first time the importance of distinguishing between different types of cruelty acts when studying cruelty to animals in adolescents. Furthermore, the study demonstrates the importance of defining what types of animals are included in the definition and the time scale over which cruelty acts have been committed in order for a more accurate picture of cruelty to be developed. Adolescents perceive deliberate and non-deliberate act of animal cruelty differently. Acceptance of nondeliberate cruelty acts is higher, as is the prevalence of these acts. Accidental animal cruelty acts are mostly reported by younger pet owning adolescents indicating a need for prevention interventions to this age group. The acceptability of cruelty acts plays a significant role in predicting animal cruelty, together with anti-social behaviours and place of living. However it 
475 has to be noted that this study has been conducted in a classroom setting and even though 476 complete anonymity was insured participants may have not felt completely comfortable 477 expressing themselves. This may have resulted in weaker differences between male and 478 female participants than in other studies where no authority person was present. Sensitive 479 topics such as studying cruelty towards animals may result in participants answering in 480 accordance to what they perceive as most acceptable in society (Fisher, 1993).

481

482 
Arluke, A. (2002). Animal abuse as dirty play. Symbolic Interaction, 25(4), 405-430.

Ascione, F. R. (1993). Children who are cruel to animals: A review of research and implications for developmental psychopathology. Anthrozoos: A Multidisciplinary Journal of The Interactions of People \& Animals, 6(4), 226-247.

Ascione, F. R., \& Lockwood, R. (2001). Cruelty to animals: Changing psychological, social, and legislative perspectives. The state of the animals, 39-54.

Ascione, F. R., Thompson, T. M., \& Black, T. (1997). Childhood cruelty to animals: Assessing cruelty dimensions and motivations. Anthrozoos: A Multidisciplinary Journal of The Interactions of People \& Animals, 10(4), 170-177.

Baldry, A. C. (2003). Animal abuse and exposure to interparental violence in Italian youth. Journal of Interpersonal Violence, 18(3), 258-281.

Baldry, A. C. (2004). The development of the PET Scale for the measurement of physical and emotional tormenting against animals in adolescents. Society and Animals, 12(1), 1-17.

Batista-Foguet, J. M., Fortiana, J., Currie, C., \& Villalbii, J. R. S.-e. i. i. s. f. c. b. c. (2004). Socio-economic indexes in surveys for comparisons between countries. Social Indicators Research, 67(3), 315332.

Becker, F. (2001). The links between child abuse and animal abuse: NSPCC London.

Becker, K. D., Stuewig, J., Herrera, V. M., \& McCloskey, L. A. (2004). A study of firesetting and animal cruelty in children: Family influences and adolescent outcomes. Journal of the American Academy of Child \& Adolescent Psychiatry, 43(7), 905-912.

Boat, B. W. (1999). Abuse of children and abuse of animals: Using the links to in-form child assessment and protection. . In I. F. A. P. Arkow (Ed.), Child abuse, domestic violence, and animal abuse: Linking the circles of compassion for prevention and interventio (pp. 83-100). West Lafayette: Purdue University Press.

Covert, A. M., Whiren, A. P., Keith, J., \& Nelson, C. (1985). Pets, Early Adolescents, and Families Marriage \& Family Review, 8(3-4), 95-108.

Dadds, M. R., Whiting, C., Bunn, P., Fraser, J. A., Charlson, J. H., \& Pirola-Merlo, A. (2004). Measurement of Cruelty in Children: The Cruelty to Animals Inventory. Journal of Abnormal Child Psychology, 32(3), 321-334. doi:10.1023/B:JACP.0000026145.69556.d9\#page-1

DeGue, S., \& DiLillo, D. (2009). Is animal cruelty a "red flag" for family violence? Investigating cooccurring violence toward children, partners, and pets. Journal of Interpersonal Violence, 24(6), 1036-1056.

Duncan, A., \& Miller, C. (2002). The impact of an abusive family context on childhood animal cruelty and adult violence. Aggression and Violent Behavior, 7(4), 365-383.

Duncan, A., Thomas, J. C., \& Miller, C. (2005). Significance of family risk factors in development of childhood animal cruelty in adolescent boys with conduct problems. Journal of Family Violence, 20(4), 235-239.

Flynn, C. P. (1999a). Animal abuse in childhood and later support for interpersonal violence in families. Society \& Animals: Journal of Human-Animal Studies, 7(2), 161-172. doi:10.1163/156853099X00059

Flynn, C. P. (1999b). Exploring the link between corporal punishment and children's cruelty to animals. Journal of Marriage and the Family, 61, 971-981.

Flynn, C. P. (2000). Why family professionals can no longer ignore violence toward animals. Family Relations, 49(1), 87-95.

Flynn, C. P. (2001). Acknowledging the" Zoological connection": A sociological analysis of animal cruelty. Society and Animals, 9(1), 71-87.

Gleyzer, R., Felthous, A. R., \& Holzer, C. E. (2002). Animal cruelty and psychiatric disorders. Journal of the American Academy of Psychiatry and the Law Online, 30(2), 257-265. 
Gullone, E., \& Robertson, N. (2008). The relationship between bullying and animal abuse behaviors in adolescents: The importance of witnessing animal abuse. Journal of Applied Developmental Psychology, 29(5), 371-379. doi:10.1016/j.appdev.2008.06.004

Hardt, J., \& Rutter, M. (2004). Validity of adult retrospective reports of adverse childhood experiences: review of the evidence. Journal of Child Psychology and Psychiatry, 45(2), 260-273. doi:10.1111/j.1469-7610.2004.00218.x

Henry, B. C. (2004). The relationship between animal cruelty, delinquency, and attitudes toward the treatment of animals. Society and Animals, 12(3), 185-207.

Henry, B. C., \& Sanders, C. E. (2007). Bullying and animal abuse: is there a connection? Society and animals, 15(2), 107-126.

Hensley, C., \& Tallichet, S. E. (2005a). Animal cruelty motivations: assessing demographic and situational influences. J Interpers Violence, 20(11), 1429-1443. doi:10.1177/0886260505278714

Hensley, C., \& Tallichet, S. E. (2005b). Learning to be cruel?: Exploring the onset and frequency of animal cruelty. International Journal of Offender Therapy and Comparative Criminology, 49(1), 37-47.

Hensley, C., \& Tallichet, S. E. (2008). The Effect of Inmates' Self-Reported Childhood and Adolescent Animal Cruelty Motivations on the Number of Convictions for Adult Violent Interpersonal Crimes. International Journal of Offender Therapy and Comparative Criminology, 52(2), 175184.

Hensley, C., \& Tallichet, S. E. (2009). Childhood and adolescent animal cruelty methods and their possible link to adult violent crimes. Journal of interpersonal violence, 24(1), 147-158.

Hensley, C., Tallichet, S. E., \& Singer, S. D. (2006). Exploring the possible link between childhood and adolescent bestiality and interpersonal violence. Journal of Interpersonal Violence, 21(7), 910923.

Herzog, H. A. (2007). Gender differences in humananimal interactions: A review. Anthrozoos: A Multidisciplinary Journal of The Interactions of People \& Animals, 20(1), 7-21.

Kellert, S. R., \& Felthous, A. R. (1985). Childhood cruelty toward animals among criminals and noncriminals. Human Relations.

Lea, S. G., \& Stock, B. (2007). Animal Abuse: Hardening childrens heart. Proteus, 1(1), 37-43.

Loeber, R., Farrington, D. P., Stouthamer-Loeber, M., \& Van Kammen, W. B. (1998). Antisocial behavior and mental health problems: Explanatory factors in childhood and adolescence.

Lucia, S., \& Killias, M. (2011). Is animal cruelty a marker of interpersonal violence and delinquency? Results of a Swiss National Self-Report study. Psychology of Violence, 1(2), 93.

Marsa-Sambola, F., Muldoon, J., Williams, J., Lawrence, A., Connor, M., \& Currie, C. (2016). The Short Attachment to Pets Scale (SAPS) for Children and Young People: Development, Psychometric Qualities and Demographic and Health Associations. Child Indicators Research, 9(1), 111-131. doi:10.1007/s12187-015-9303-9

McPhedran, S. (2009a). Animal Abuse, Family Violence, and Child Wellbeing: A Review. Journal of Family Violence, 24(1), 41-52. doi:10.1007/s10896-008-9206-3

McPhedran, S. (2009b). A review of the evidence for associations between empathy, violence, and animal cruelty. Aggression and Violent Behavior, 14(1), 1-4. doi:10.1016/j.avb.2008.07.005

Miller, K. S., \& Knutson, J. F. (1997). Reports of severe physical punishment and exposure to animal cruelty by inmates convicted of felonies and by university students. Child Abuse \& Neglect, 21(1), 59-82.

Murray, J. K., Browne, W. J., Roberts, M. A., Whitmarsh, A., \& Gruffydd-Jones, T. J. (2010). Number and ownership profiles of cats and dogs in the UK. Vet Rec, 166(6), 163-168. doi:10.1136/vr.b4712

Pagani, C., Robustelli, F., \& Ascione, F. R. (2010). Investigating animal abuse: Some theoretical and methodological issues. Anthrozoos: A Multidisciplinary Journal of The Interactions of People \& Animals, 23(3), 259-276. 
583

584

585

586

587

588

589

590

591

592

593

594

595

596

597

598

599
Paul, E. S. (2000). Empathy with animals and with humans: Are they linked? Anthrozoos: A Multidisciplinary Journal of The Interactions of People \& Animals, 13(4), 194-202.

Simons, D. A., Wurtele, S. K., \& Durham, R. L. (2008). Developmental experiences of child sexual abusers and rapists. Child Abuse Negl, 32(5), 549-560. doi:10.1016/j.chiabu.2007.03.027

Tallichet, S. E., \& Hensley, C. (2004). Exploring the link between recurrent acts of childhood and adolescent animal cruelty and subsequent violent crime. Criminal Justice Review, 29(2), 304316.

Tallichet, S. E., \& Hensley, C. (2005). Rural and urban differences in the commission of animal cruelty. International Journal of Offender Therapy and Comparative Criminology, 49(6), 711-726.

Tallichet, S. E., \& Hensley, C. (2009). The Social and Emotional Context of Childhood and Adolescent Animal Cruelty Is There a Link to Adult Interpersonal Crimes? International Journal of Offender Therapy and Comparative Criminology, 53(5), 596-606.

Tallichet, S. E., Hensley, C., \& Singer, S. D. (2005). Unraveling the methods of childhood and adolescent cruelty to nonhuman animals. Society and Animals, 13(2), 91-108.

Taylor, N., \& Signal, T. D. (2005). Empathy and attitudes to animals. Anthrozoos: A Multidisciplinary Journal of The Interactions of People \& Animals, 18(1), 18-27. 
600

' Local authorities in Scotland encompass all school districts within the authority. 